\title{
Relationship of Glycosylated Hemoglobin with Fasting Plasma Glucose and 2 Hours After Breakfast Plasma Glucose in Type 2 Diabetes
}

\author{
Sheikh Salahuddin Ahmed ${ }^{1}$, Tarafdar Runa Laila ${ }^{1}$, Fazle Nur ${ }^{2}$, Mamun Ul Islam Khan ${ }^{2}$, \\ Umme Sadia Mili², Md. Abdul Mahid Khan ${ }^{3}$, Mohammad Rafiqul Hoque ${ }^{4}$ \\ ${ }^{1}$ Faculty of Medicine, Universiti Kuala Lumpur, Royal College of Medicine Perak, No. 3, Jalan Greentown, Ipoh, Perak, Malaysia \\ ${ }^{2}$ Department of Endocrinology, Bangladesh Institute of Health Sciences and Hospital, Mirpur, Bangladesh \\ ${ }^{3}$ Department of Internal Medicine (Cardiology), Gastro Liver Hospital \& Research Institute Ltd, Dhaka, Bangladesh \\ ${ }^{4}$ Department of Biochemistry, Shahid Syed Nazrul Islam Medical College, Kishoreganj, Bangladesh
}

Email address:

drsksalahahmed@yahoo.com (S. S. Ahmed)

\section{To cite this article:}

Sheikh Salahuddin Ahmed, Tarafdar Runa Laila, Fazle Nur, Mamun Ul Islam Khan, Umme Sadia Mili, Md. Abdul Mahid Khan, Mohammad Rafiqul Hoque. Relationship of Glycosylated Hemoglobin with Fasting Plasma Glucose and 2 Hours After Breakfast Plasma Glucose in Type 2 Diabetes. American Journal of Internal Medicine. Vol. 3, No. 4, 2015, pp. 160-164. doi: 10.11648/j.ajim.20150304.13

\begin{abstract}
Background: Glycosylated hemoglobin (HbAlc), fasting plasma glucose (FPG) and 2 hours (2-hr) after breakfast $(\mathrm{ABF})$ plasma glucose, are often used to monitor and manage glycemia in stable diabetic patients. Data regarding the relationship and relative contribution of FPG and 2-hr ABF plasma glucose to HbA1c level in Type 2 diabetes mellitus (T2DM) are insufficient. Objective: To examine the correlation of FPG, and 2-hr ABF with HbA1c in known patients having T2DM; and to find out which one of FPG and ABF is the dominant contributor to overall glycemia in monitoring diabetes. Study Design and Methods: The study was carried on 664 known T2DM patients under treatment and routine follow-up at a tertiary care hospital in Bangladesh. FPG \& 2-hr ABF plasma glucose concentrations were measured by hexokinase method. HbA1c was measured by high performance liquid chromatography based hemoglobin assay system. The Pearson correlation coefficient was used to investigate the relationship of FPG and ABF with HbA1c and their significance. Results: Both FPG and ABF levels were correlated with $\mathrm{HbA1c}$ but higher correlation was seen between FPG and HbA1c. The correlation coefficients between FPG and $\mathrm{HbA1c}$ and between $\mathrm{ABF}$ and $\mathrm{HbAlc}$ were 0.722 and 0.664 respectively. Both the correlations were found statistically significant $(\mathrm{p}<0.001)$. Conclusion: In patients with T2DM, FPG and ABF both were significantly correlated with HbA1c; and in our study we found that overall correlation of HbA1c with FPG was higher than ABF plasma glucose level.
\end{abstract}

Keywords: Glycosylated Hemoglobin, Fasting Plasma Glucose, 2 Hours After Breakfast, Diabetes Mellitus

\section{Introduction}

Type 2 diabetes mellitus (T2DM) is a major public health problem. The microvascular and macrovascular complications of DM are well known. T2DM remains the leading cause of end-stage renal failure, cardiovascular disorders, blindness, non-traumatic lower limb amputations, and hospitalizations. According to International Diabetes Federation the global pandemic of T2DM is increasing and it is found same for Bangladesh [1]. An estimated 366 million people worldwide had diabetes in 2011 and this number is projected to reach 552 million in 2030 [1]. Among the top ten, Bangladesh was in the eighth position (8.4 million patients having diabetes) in 2011 ; and as projected in the report the country will occupy fifth position in 2030 (16.8 million people will have diabetes) [1]. Therefore it has become necessary to diagnose diabetes early and take appropriate measures to maintain good glycemic control; thereby preventing diabetes related complications, morbidity and mortality.

T2DM is characterized by chronic hyperglycemia, which is the consequence of both fasting and post-meal hyperglycemia. Both fasting plasma glucose (FPG) and postprandial plasma glucose (PPG) are directly correlated to the risk of complications, with some evidence that postprandial hyperglycemia might constitute a stronger risk factor for cardiovascular complications [2-4].

Optimal glycemic control is fundamental to the 
management of diabetes. FPG and PPG are used to monitor and manage diabetes; Glycosylated hemoglobin ( $\mathrm{HbAlc})$ is also widely used in the management of diabetes both as a measure of glycemic control and as a predictor of risk for diabetes complications $[5,6]$. An initial HbA1c is also recommended to assess the severity of the condition and as a guide of initiating therapy [7]. FPG and PPG level reflect the state of recent glycemia whereas $\mathrm{HbAlc}$ level reflects chronic glycemia. HbAlc indicates an average of blood glucose levels over the past 2-3 months [8-10]. Because $\mathrm{HbA1c}$ testing is a bit expansive, everybody cannot afford it in Bangladesh. FPG along with the most commonly used index of PPG, as for example plasma glucose 2 hours after breakfast (2-hr ABF), are used for monitoring glycemic status in diabetic patients attending outpatient department of the hospitals of Bangladesh.

As FPG and 2-hr ABF are used to monitor and manage glycemia in diabetic patients, the knowledge of correlation of FPG and ABF with HbAlc may be helpful in the management of T2DM to achieve optimum glycemic control. The exact contributions of PPG and FPG to overall glycemia remain controversial. There are limited evidence to suggest which one among the FPG and 2-hr ABF is the dominant contributor to overall glycemia in patients with T2DM. Our aim was to examine the correlation of HbA1c with FPG and 2-hr ABF plasma glucose in patients with $\mathrm{T} 2 \mathrm{DM}$; and to find out the dominant contributor (FPG or 2-hr ABF) to overall glycemia.

\section{Study Design and Methods}

This observational study was conducted from July 2013 to December 2013 in the out-patient department of Bangladesh Institute of Health Sciences (BIHS) and Hospital, Dhaka, an enterprise of Bangladesh Diabetic Association. The target population of this study was known adult patients having T2DM and the sample size was 664. It was a cross sectional study and the patients were randomly selected fulfilling the inclusion $\&$ exclusion criteria from the patients reporting to the consultants for their follow up and monitoring. The patients were on treatment for diabetes and reporting for review and follow-up.

Inclusion criteria:

*Adult ( $>18$ years) male and female Bangladeshi patients.

*Suffering from T2DM under treatment.

Exclusion Criteria:

*Unwilling to be included in the study.

*Patients having factors that influence HbAlc other than diabetes.

*Persons with mental illness.

*Pregnant diabetic patient.

The participants were interviewed face to face and clinical examinations were carried out by the consultants or the health care providers. Samples for FPG, 2-hr ABF and HbA1c were collected from the antecubital vein in the BIHS laboratory accordingly. Analysis for plasma glucose was done by hexokinase enzymatic method using kits manufactured by Siemens Health Care Ltd by Dimension RxL Max automated chemistry analyzer. HbA1c was measured by cation-exchange high-pressure liquid chromatography using D-10 ${ }^{\mathrm{TM}}$ (BioRad, USA) hemoglobin assay system. The laboratory results along with the relevant clinical findings were endorsed in the semi-structured data collection sheet. All the responses obtained from the patients were coded numerically and analyzed using Statistical Package for Social Science (SPSS) version 16 software. The Pearson correlation coefficient (r) was used to investigate the relationship of FPG and 2-hr ABF with $\mathrm{HbA1c}$. A p value of $<0.05$ was considered statistically significant.

\section{Results}

The background, clinical and glycemic characteristics of the study population is shown in Table 1 and Table 2 . The mean age was found to be 53.5 years, male being $44.1 \%$ and female $55.9 \%$. HbA1c levels in $8 \%$ of subject was $\leq 6.5 \%$ while $51.8 \%$ had values $>8.5 \%$. The mean values of $\mathrm{HbAlc}$, FPG and $2-\mathrm{hr}$ ABF were $9.0 \%, 8.5 \mathrm{mmol} / \mathrm{L}$ and $12.2 \mathrm{mmol} / \mathrm{L}$ respectively. The correlation coefficient of HbA1c (Table 3) with FPG was $0.722(\mathrm{p}<0.001)$ and with $2-\mathrm{hr}$ ABF was $0.664(\mathrm{p}<0.001)$. Both correlations were seen positive, moderate and statistically significant. The overall relationship of $\mathrm{HbA1c}$ with FPG was found to be more closely correlated as compared to that of HbA1c with ABF ( $r=0.722$ versus 0.664). We found the correlation between FPG and 2-hr ABF to be positive $(r=0.773)$, moderate and highly significant $(\mathrm{p}<0.001)$. The scatter plot graphs with regression lines for the correlation of $\mathrm{HbAlc}$ with FPG and ABF are shown in Figure 1 and Figure 2. The figures show that there is a definite linear relationship between $\mathrm{HbA} 1 \mathrm{c}$ with FPG and that of ABF values and both values of FPG and $\mathrm{ABF}$ are positively correlated with $\mathrm{HbAlc}$.

Table 1. Back ground characteristics $(n=664)$.

\begin{tabular}{lll}
\hline Variables & $\mathbf{n}$ & $\mathbf{\%}$ \\
\hline Age group (years) & & \\
$27-40$ & 75 & 11.3 \\
$41-50$ & 207 & 31.2 \\
$51-60$ & 221 & 33.3 \\
$>60$ & 161 & 24.2 \\
Sex & & \\
Male & 293 & 44.1 \\
Female & 371 & 55.9 \\
Residence & & \\
Urban & 527 & 79.3 \\
Semi-urban & 84 & 12.7 \\
Rural & 53 & 08.0 \\
Highest level of education & & \\
None & 88 & 13.3 \\
Junior school & 209 & 31.5 \\
Higher secondary & 216 & 32.5 \\
Graduates and above & 151 & 22.7 \\
Associated comorbidities & & \\
Hypertension & 415 & 62.5 \\
Dyslipidemia & 368 & 55.4 \\
Fatty liver & 182 & 27.4 \\
Early diabetic nephropathy & 118 & 17.8 \\
*IHD & 105 & 15.8 \\
*CVD & 20 & \\
Glycemic status (HbAlc) & & \\
\hline & & \\
\hline & & \\
\hline
\end{tabular}




\begin{tabular}{lll}
\hline Variables & n & \% \\
\hline HbA1c 6.5 or less & 53 & 08.0 \\
HbA1c 6.6 to 8.5 & 267 & 40.2 \\
HbA1c $>8.5$ & 344 & 51.8 \\
\hline
\end{tabular}

*IHD, ischemic heart disease; CVD, cerebrovascular disease

Table 2. Clinical and glycemic features $(n=664)$.

\begin{tabular}{lll}
\hline Variables & Mean $( \pm$ SD) & SE of mean \\
\hline $\begin{array}{l}\text { Age (years) } \\
\text { Weight }(\mathrm{kg})\end{array}$ & $53.47 \pm 1.04$ & .40 \\
Male $(\mathrm{kg})$ & & \\
Female $(\mathrm{kg})$ & $68.68 \pm 9.77$ & .570 \\
Height & $63.42 \pm 1.05$ & .547 \\
Male $\left(\mathrm{m}^{2}\right)$ & & \\
Female $\left(\mathrm{m}^{2}\right)$ & $1.63 \pm 0.06$ & .003 \\
BMI $\left(\right.$ Kg/ $\left.{ }^{2}\right)$ & $1.52 \pm 0.05$ & .002 \\
Male & & \\
Female & $25.82 \pm 3.40$ & .198 \\
Blood Pressure & $27.20 \pm 4.34$ & .225 \\
Systolic (mmHg) & & \\
Diastolic (mm Hg) & $129.8 \pm 14.8$ & .57 \\
Overall glycemia & $81.3 \pm 8.1$ & .31 \\
HbA1c \% & & \\
FPG (mmol/L) & $9.0 \pm 2.1$ & .082 \\
ABF (mmol/L) & $8.5 \pm 3.2$ & .124 \\
\hline
\end{tabular}

Table 3. Pearson's correlation coefficient $(n=716)$.

\begin{tabular}{lll}
\hline Variables correlated & Pearson's correlation coefficient & p value \\
\hline HbA1c with FPG & 0.722 & $<0.001$ \\
HbA1c with ABF & 0.664 & $<0.001$ \\
FPG with ABF & 0.773 & $<0.001$ \\
\hline
\end{tabular}

\section{Discussion}

In this study, we correlated $\mathrm{HbA1c}$ with FPG as well as with 2-hr ABF in patients with T2DM. Both FPG and ABF levels were found to be positively correlated with $\mathrm{HbAlc}$. But the correlation of $\mathrm{HbAlc}$ with FPG was found to be higher $(\mathrm{r}=0.722)$ than that with $2-\mathrm{hr}$ ABF plasma glucose $(\mathrm{r}=0.664)$. Both FPG and ABF contributed to overall glycemia but contribution by FPG was found to be relatively more than by 2-hr ABF plasma glucose in our study population where $51.8 \%$ had $\mathrm{HbAlc}>8.5 \%$.

Our findings are consistent with the studies of Bonora et al., Saiedullah et al., Hossain et al. and Gupta et al. [11-14]. Bonora et al., in their study on T2DM ( $\mathrm{n}=371)$ observed that $\mathrm{HbA1c}$ has close relation to FPG and not to the PPG level [11]. They concluded that FPG measurements are more closely related to HbA1c than PPG. One study done in Bangladesh by Saiedullah et al. revealed that FPG had a modest higher relation with $\mathrm{HbA1c}$ than 2-hr after oral glucose load in the newly diagnosed 347 diabetic subjects [12]. In their study the Pearson's correlation coefficient of FPG and PPG with HbA1c in the diabetic subjects were $0.8012(\mathrm{p}<0.001)$ and 0.7812 $(\mathrm{p}<0.001)$ respectively. They concluded that evaluation of FPG may provide better outcome than PPG in the newly diagnosed never treated diabetic subjects. Hossain et al. also had a similar type of study among 428 newly diagnosed cases of diabetes in Bangladesh [13]. They correlated the FPG and plasma glucose 2-hr after oral glucose load with $\mathrm{HbAlc}$; the
Pearson's correlation coefficient were $0.551 \quad(\mathrm{p}<0.001)$ and $0.475(\mathrm{p}<0.001)$ respectively.

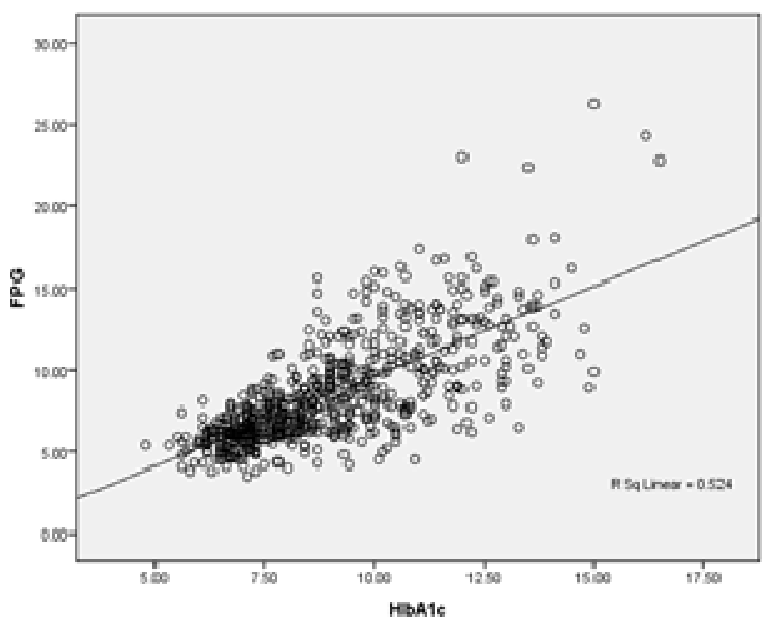

Figure 1. Scatter plot (bivariate) graph showing correlation of glycosylated hemoglobin $(\mathrm{HbAlc}$ ) with fasting plasma glucose (FPG). HbAlc is expressed in \%; FPG value is expressed in $\mathrm{mmol} / \mathrm{L}$.

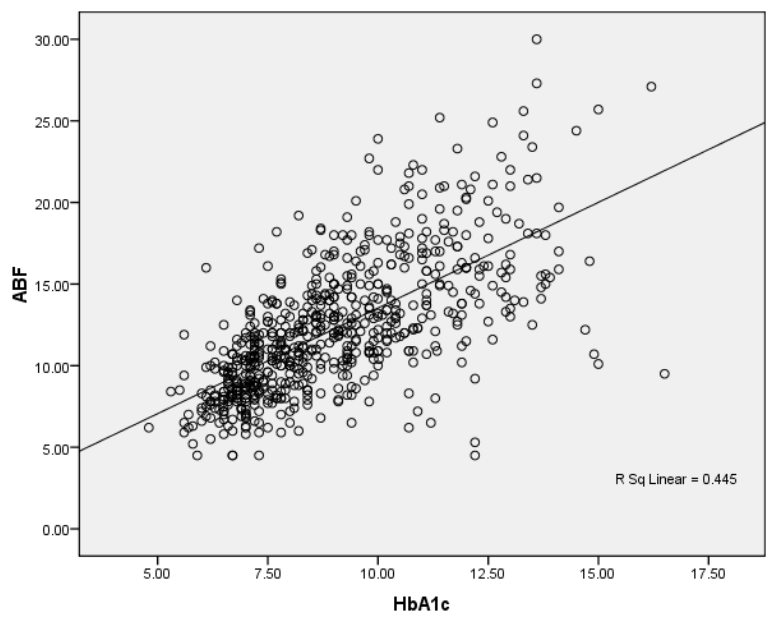

Figure 2. Scatter plot (bivariate) graph showing correlation of glycosylated hemoglobin (HbAlc) with 2 hours after breakfast $(A B F)$ plasma glucose. $H b A 1 c$ is expressed in \% and ABF value in $\mathrm{mmol} / \mathrm{L}$.

In a study on 50 patients of T2DM in India, done by Gupta et al., $\mathrm{HbA} 1 \mathrm{c}$ levels in $20 \%$ of patients were $<6.5 \%$ while $80 \%$ had values $>6.5 \%$ [14]. Both FPG as well as PPG levels (one sample taken 2-hr after meal) were correlated with $\mathrm{HbAlc}$ but higher correlation was seen between FPG and $\mathrm{HbAlc}$ $(\mathrm{r}=0.685$ versus $\mathrm{r}=0.623)$. They concluded that $\mathrm{FPG}$ value appreciably contributes $\mathrm{HbA} 1 \mathrm{c}$ as compared to post-meal glucose values. Carroll et al. evaluated the relationship of FPG to PPG and concluded that the FPG level predicts the degree of post-meal hyperglycemia and the magnitude of the post-meal excursion from baseline [15]. The authors concluded that, because FPG is a determinant of PPG excursion, "fixing the fasting" should precede PPG correction.

Our results are not in accordance with the studies of Masram et al., Azim et al., Shahram et al. and Rosediani et al. who revealed that PPG has a stronger correlation with $\mathrm{HbAlc}$ 
as compared to the FPG [16-19]. The total number of T2DM subjects investigated in the study of Masram et al. was fifty [16]. Azim et al. concluded that PPG has a stronger correlation with $\mathrm{HbA1c}$ as compared to the FPG; so a strict monitoring and control of PPG can help the clinicians to have an economical alternative test, compared to $\mathrm{HbAlc}$ for glycemic control for their uncomplicated diabetic patients [17]. Shahram et al. in their study with 237 patients of T2DM showed that the correlation coefficient of plasma glucose level and $\mathrm{HbA} 1 \mathrm{c}$ cases were 0.316 for FPG and 0.425 for 2-hr ABF. They concluded that the PPG (2-hr ABF) has closer association to $\mathrm{HbAlc}$ than FPG; therefore evaluating PPG should be the focus [18]. Rosediani et al. in their study on 82 patients of T2DM, found better correlation of ABF to $\mathrm{HbA} 1 \mathrm{c}$ than that of FPG ( $\mathrm{r}=0.604$ versus 0.575 ) and concluded that PPG predicts overall glycemic control better than FPG [19].

The study of Monnier et al. suggested that FPG levels represent the major contributor to overall hyperglycemia at higher HbA1c levels $(>10.2 \%)$, while PPG is the dominant contributor in patients with good to moderate glycemic control (HbAlc $<8.5 \%$ ) [20]. In our study the majority of the patients had $\mathrm{HbA} 1 \mathrm{c}$ level $>8.5 \%$, which may explain the overall closer relationship of HbAlc with FPG than 2-hr ABF. The FPG is more consistent and reproducible than PPG because there are more variables in the latter, such as timing and carbohydrate load [21]. The variables of food intake and exercise are much less of a factor at night preceding measurement of the FPG, and this may enable a more consistent pattern of values for FPG. According to recommendations of American Diabetes Association, pre-prandial glucose is targeted first [22]. Only when pre-prandial glucose is controlled, but $\mathrm{HbA} 1 \mathrm{c}$ is not, PPG should be targeted. In present study both FPG and PPG were found significantly correlated with HbAlc. This suggests that correcting both will help to achieve a good glycemic control. The Diabetes Control and Complications trial and Research Group (1993) suggested that one should aim at controlling plasma glucose not only in the fasting state but throughout the day to achieve better long-term glycemic control and minimize the risk of chronic diabetic complications [8].

\section{Conclusion}

The study revealed that $\mathrm{HbA} 1 \mathrm{c}$ has significant and positive correlations with FPG and 2-hr ABF plasma glucose. HbA1c was found to have higher correlation with FPG than 2-hr ABF plasma glucose level in our study population where majority had a mean $\mathrm{HbA} 1 \mathrm{c}$ value of $\geq 8.5 \%$. Thus correcting both FPG and $\mathrm{ABF}$ will help to achieve a good glycemic control in patients with T2DM that can prevent diabetes related complications, morbidity and mortality.

\section{Conflict of Interest}

The authors declare no conflict of interest relevant to this article.

\section{Funding Sources}

The authors received no financial support for the research, authorship, and publication of this article.

\section{References}

[1] Whiting DR, Guariguata L, Weil C, Shaw J. IDF Diabetes Atlas: Global estimates of the prevalence of diabetes for 2011 and 2030. Diabetes Res Clin Pract 2011 (Dec);94(3):311-21.

[2] Service FJ, O'Brien PC. The relation of glycaemia to the risk of development and progression of retinopathy in the Diabetic Control and Complications Trial. Diabetologia 2001;44(10):1215-20.

[3] Sorkin JD, Muller DC, Fleg JL, Andres R. The relation of fasting and 2-h postchallenge plasma glucose to mortality: data from the Baltimore Longitudinal Study of Aging with a critical review of the literature. Diabetes Care 2005;28:2626-32.

[4] Cavalot F, Pagliarino A, Valle M, Martino LD, Bonomo K, Massucco $\mathrm{P}$, et al. Postprandial blood glucose predicts cardiovascular events and all-cause mortality in type 2 diabetes in a 14-year follow-up: lessons from the San Luigi Gonzaga Diabetes Study. Diabetes Care 2011;34:2237-43.

[5] Albers JW, Herman WH, Pop-Busui R, Feldman EL, Martin CL, Cleary PA, et al. Diabetes Control and Complications Trial/Epidemiology of Diabetes Interventions and Complications Research Group. Effect of prior intensive insulin treatment during the Diabetes Control and Complications Trial (DCCT) on peripheral neuropathy in type 1 diabetes during the Epidemiology of Diabetes Interventions and Complications (EDIC) study. Diabetes Care 2010;33:1090-96.

[6] Stratton IM, Adler AI, Neil HAW, Matthews DR, Manley SE, Cull CA, et al. Association of glycaemia with macrovascular and microvascular complications of type 2 diabetes (UKPDS 35): prospective observational study. BMJ 2000;321:405-12.

[7] Handelsman Y, Mechanick JI, Blonde L, Grunberger G, Bloomgarden ZT, Bray GA, et al. American Association of Clinical Endocrinologists Medical Guidelines for Clinical Practice for Developing a Diabetes Mellitus Comprehensive Care Plan. Endocr Pract 2011;17(Suppl 2):1-53

[8] Diabetes Control and Complications Trial Research Group, 'The effect of intensive treatment of diabetes on development and progression of long term complications in insulin dependent diabetes mellitus', N Engl J Med 1993;329:977-86.

[9] UK Prospective Diabetes Study Group, Intensive blood glucose with sulphonylureas or insulin compared with conventional treatment and risk of complications in patients with type 2 diabetes. Lancet 1998;352:837-53.

[10] Sacks DB, Arnold M, Bakris GL, Bruns DE, Horvath AR, Kirkman MS et al. National Academy of Clinical Biochemistry. Position statement executive summary: guidelines and recommendations for laboratory analysis in the diagnosis and management of diabetes mellitus. Diabetes Care 2011;34:1419-23.

[11] Bonora E, Calcaterra F, Lombardi S, Bonfante N, Formentini G, Bonadonna RC, et al. Plasma glucose levels throughout the day and $\mathrm{HbAlC}$ interrelationships control in type 2 diabetes: implications for treatment and monitoring of metabolic control. Diabetes Care 2001 Dec;24(12):2023-29. 
[12] Saiedullah M, Begum S, Shermin S, Rahman MR, Khan MAH. Relationship of glycosylated hemoglobin with fasting and postprandial plasma glucose in nondiabetic, pre-diabetic and newly diagnosed diabetic subjects. Bangladesh Med J 2011;40:37-38.

[13] Hossain T, Latif ZA, Sarkar AA. Relationship of HbAlc with Fasting and Plasma Glucose 2 Hours after Oral Glucose Load in Non Diabetic and Newly Diagnosed Pre Diabetic and Diabetic Patients. Birdem Med J 2012;2(2):81-83.

[14] Gupta S, Puppalwar PV, Chalak A. Correlation of fasting and post meal plasma glucose level to increased HbAlc levels in type-2 diabetes mellitus. Int J Adv Med 2014;1:127-31.

[15] Carroll M, Izard A, Riboni K, Burge M, Schade D: Fasting hyperglycemia predicts the magnitude of postprandial hyperglycemia. Diabetes Care 2002;25:1247-48.

[16] Masram SW, Bimanpalli MV. Assessment of contribution of fasting and post meal plasma glucose to increased $\mathrm{HbA1C}$ in diabetes mellitus-comparative study. Int J Biol Med Res 2012;3(3):2020-24.

[17] Azim W, Mushtaq GM, Azim S, Farooq W. Assessment of fasting and two-hour post-prandial glucose as an economical test for monitoring of glycemic control, compared to glycated haemoglobin. Med Channel 2011;17(2):5-7.

[18] Shahram H, Ghazaleh N. Relation of fasting and postprandial plasma glucose with hemoglobinAlc in diabetics. Int $\mathrm{J}$ Diabetes Dev Ctries 2010 Jan-Mar;30(1):8-10.

[19] Rosediani M, Azidah AK, Mafauzy M. Correlation between fasting plasma glucose, post prandial glucose and glycated haemoglobin and fructosamine. Med J Malaysia 2006 Mar;61(1):67-71.

[20] Monnier L, Lapinski H, Colette C. Contributions of fasting and postprandial plasma glucose increments to the overall diurnal hyperglycemia of type 2 diabetic patients: variations with increasing levels of HbA1c. Diabetes Care 2003;26:881-85.

[21] Sacks DB, Bruns DE, Goldstein DE, Maclaren NK, McDonald JM, Parrott M. Guidelines and recommendations for laboratory analysis in the diagnosis and management of diabetes mellitus. Clin Chem 2002;48(3):436-72.

[22] American Diabetes Association: Postprandial blood glucose (Consensus Statement). Diabetes Care 2001;24:775-78. 